\title{
Downhole Fluid Analysis
}

\author{
Oliver C. Mullins, Schlumberger.
}

\section{Abstract}

Recently, a new model of asphaltenes, the modified Yen model,[1] has been proposed to account for their nanocolloidal structure in solvents and more importantly in crude oil. This model has found utility in treating asphaltene gradients in reservoirs, especially with asphaltene instability for example induced by a late gas charge into the reservoir.[2] In particular, this model provides a mechanism of asphaltene instability at the top of the column producing a tar mat at the base of the column. Utilizing the new technology Downhole Fluid Analysis [3], asphaltene gradients can be measured with unstable asphaltenes (often) identified; implications for this 'allochthonous' tar mat formation follow. Consequently, there is a single framework to treat asphaltene and viscosity gradients along with tar mats. This framework relies on the physical destabilization of asphaltenes as opposed to autochthonous tar mat formed by biodegradation at the oil-water contact. Field case studies are the path forward.

[1] O.C. Mullins, The Modified Yen Model, Energy \& Fuels, 24, 2179-2207, (2010).

[2] O.C. Mullins, D.E. Freed, J.Y. Zuo, H Elshahawi, M.E. Cribbs, V.K. Mishra, A. Gisolf, Downhole Fluid Analysis coupled with Asphalene Nanoscience for Reservoir Evaluation, Accepted SPWLA, (2010).

[3] O.C. Mullins, The Physics of Reservoir Fluids; Discovery through Downhole Fluid Analysis, Schlumberger Press, Houston, TX (2008). 